\title{
Glutathione transferases P1/P2 regulate the timing of signaling pathway activations and cell cycle progression during mouse liver regeneration
}

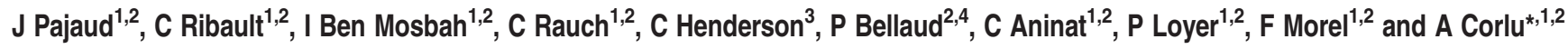

Glutathione transferases (GST) are phase II enzymes catalyzing the detoxification of endogenous noxious compounds and xenobiotics. They also regulate phosphorylation activities of MAPKinases in a catalytic-independent manner. Previous studies have demonstrated the regulation of JNK-dependent pathway by GSTP1/2. Considering the crucial role of JNK in the early steps of the hepatocyte cell cycle, we sought to determine whether GSTP1/2 were essential for hepatocyte proliferation following partial hepatectomy (PH). Using a conventional double knockout mouse model for the Gstp1 and Gstp2 genes, we found that the lack of GSTP1/P2 reduced the rate of DNA replication and mitotic index during the first wave of hepatocyte proliferation. The lowered proliferation was associated with the decrease in TNFalpha and IL-6 plasma concentrations, reduced hepatic HGF expression and delayed and/or altered activation of STAT3, JNK and ERK1/2 signaling pathways. In addition, the expression and/or activation of cell cycle regulators such as Cyclin D1, CDK4, E2F1 and MCM7 was postponed demonstrating that the absence of GSTP1/2 delayed the entry into and progression through the G1 phase of the cell cycle and impaired the synchrony of proliferation in hepatocytes following PH. Furthermore, while JNK and its downstream targets c-Jun and ATF2 were activated during the early steps of the liver regeneration in wild-type animals, the constitutively active JNK found in the quiescent liver of Gstp1/2 knockout mice underwent a decrease in its activity after PH. Transient induction of antioxidant enzymes and nitric oxide synthase were also delayed or repressed during the regenerative response. Altogether our results demonstrate that GSTP1/2 are a critical regulators of hepatocyte proliferation in the initial phases of liver regeneration.

Cell Death and Disease (2015) 6, e1598; doi:10.1038/cddis.2014.562; published online 15 January 2015

Liver regeneration is a complex and sequential process allowing liver mass restoration after tissue injury. This process is controlled by multiple regulatory pathways that orchestrate both proliferative and hepatoprotective signaling cascades. It has been divided into three distinct phases: the initiation, the promotion or the proliferation step, and the termination. ${ }^{1}$ The initiation, also called priming, corresponds to the activation of the immediate-early response genes by pro-inflammatory cytokines, such as tumor necrosis factor alpha $(\mathrm{TNF} a)^{2}$ and interleulin-6 (IL-6) ${ }^{3}$ that induces the G0/G1 transition of quiescent hepatocytes. It results in inducing hepatocytes to become sensitive to growth factors and competent for replication. Among the immediate-early response genes, expression of c-Jun and c-Fos is induced to form the transcription factor AP-1 that regulates transcription of genes implicated in cell proliferation or differentiation. Induction of c-Jun requires activation of c-Jun $\mathrm{N}$-terminal kinase (JNK) through the phosphorylation on its Serine 63 and 73 residues.
The activation of JNK is therefore an early event that occurs concomitantly to NF- $K$ B activation following TNF $a$ signaling. ${ }^{4,5}$ Among the growth factors involved in the proliferation step, hepatocyte growth factor (HGF), transforming growth factor alpha (TGFa) and epidermal growth factor (EGF) induce hepatocytes to override the mitogen restriction point located at 2/3 of G1 phase. ${ }^{6}$ They activate mitogen-activated protein kinase (MAPK) pathways that induce key regulators in late G1 phase such as Cyclin D's and cyclin-dependent-kinases $4 / 6$ (CDKs), which have a critical role in the control of the G1/S transition and the commitment to DNA replication. ${ }^{7-11}$ Gene-deficient knockout mouse models have not only confirmed the importance of cytokines and growth factors but also revealed the role of metabolic networks in integrating regenerative response with maintenance of hepatic function. Despite numerous studies during the past decades, cell-extrinsic and -intrinsic molecular mechanisms governing the dynamic metabolic changes in hepatocytes

\footnotetext{
${ }^{1}$ Inserm, UMR 991, Liver, Metabolisms and Cancer, CHU Pontchaillou, Rennes, France; ${ }^{2}$ Université de Rennes 1, Faculté de Médecine, Rennes, France; ${ }^{3}$ Medical Research Institute, University of Dundee, Ninewells Hospital and Medical School, Dundee, UK and ${ }^{4}$ Plateforme Histopathologie H2P2, Biosit, Biogenouest, Université de Rennes 1, Rennes, France

*Corresponding author: A Corlu, UMR 991, Liver, Metabolisms and Cancer, CHU Pontchaillou, Rennes 35033, France. Tel: +0033 0223233870 ; Fax: +0033 0 299540137; E-mail: anne.corlu@inserm.fr

The authors would like to dedicate this article to Dr Fabrice Morel who passed away during the preparation of the manuscript. Fabrice Morel was an exceptional scientist in the field of molecular pharmacology and a friend whose enthusiasm for life and belief in science will continue to inspire all of us who were privileged to know him. Abbreviations: PH, partial hepatectomy; GST, glutathione S-transferase; GSH, glutathione; TRAF2, tumor necrosis factor receptor-associated factor 2; ASK1, apoptosis signal regulating kinase 1; MAPK, mitogen-activated protein kinase; JNK, c-jun N-terminal kinase; ERK, extracellular signal regulated kinase; MCM, minichromosome maintenance; ROS, reactive oxygen species; BrdU, 5-bromo-2'-deoxyuridine; ATF, activating transcription factor; CDK, cyclin-dependent kinase; ALT, alanine aminotransferase; AST, aspartate aminotransferase

Received 17.7.14; revised 18.11.14; accepted 19.11.14; Edited by A Finazzi-Agrò
} 
after partial hepatectomy $(\mathrm{PH})$ still remain incompletely understood.

Hemodynamic changes induced by $\mathrm{PH}$ and proinflammatory cytokines are also known to cause alteration of redox potential affecting the stress-activated signaling cascades. Glutathione transferase (GST) phase II detoxification enzymes belong to a multigenic family with seven classes (alpha, mu, pi, omega, sigma, theta, zeta). They are involved in various functions, including detoxification, biosynthesis and cell signaling. ${ }^{12-15}$ Conjugation activities of GSTs result in cell protection by eliminating noxious compounds, by protecting proteins, lipids or DNA against reactive species and by metabolizing molecules, such as prostaglandins ${ }^{16}$ and 4-hydroxy-2-nonenal. ${ }^{17}$ GSTs catalyze glutathionylation or S-glutathionylation, a reversible posttranslational modification regulating protein function, which is significantly promoted by reactive nitrogen species and reactive oxygen species (ROS). GSTs also have important roles in regulating signaling pathways in a catalytic-independent manner through direct interaction with proteins such as protein kinases to modulate their phosphorylation activities. For example, GSTA $1^{18}$ and mGSTA $4{ }^{19}$ bind to JNK, and GSTM1 interacts with apoptosis signal-regulating kinase 1 (ASK1), the kinase transducing JNK signaling, to inhibit the apoptotic pathways. ${ }^{20}$ During oxidative stress in mouse hepatocytes, it was shown that JNK is required for the induction of GSTA4 leading to the formation of mGSTA4/JNK complexes that might regulate JNK activity. ${ }^{19}$ GSTM1, GSTA1 and GSTP1 also have a key role in the regulation of $A S K 1$ phosphorylation activity in rat hepatocytes. $^{21}$ In fibroblasts 3T3/4A, GSTP1/JNK interaction occurring in the absence of stress stimuli also inhibits JNK activity and c-Jun phosphorylation. ${ }^{22}$ More recently, in osteosarcoma cells, GSTP1 has been shown to interfere not only with JNK pathway but also with tumor necrosis factor receptor-associated factor 2 (TRAF2) signaling resulting in the inhibition of P38 and JNK phosphorylation. The dissociation of the complexes leads to ASK1 activation and prolonged activation of P38 and JNK that cause cell growth arrest by increasing the expression of the CDK inhibitor P21 ${ }^{\mathrm{CIP} 1}$ and apoptosis. $^{23}$

Nowadays, there is no report on the possible involvement of GSTP1 in the regulation of liver regeneration although the crucial role of JNK pathway in the entry into and progression through G1 phase of the cell cycle in hepatocyte is well established. ${ }^{5,24}$ Using a conventional double knockout mouse model for the GstP1 and GstP2 genes, ${ }^{25}$ we investigated for the first time the impact of the absence of GSP1/P2 on liver regeneration after two-third $\mathrm{PH}$. Our data demonstrate that GSTP1/P2 contribute to the finely tuned activation levels of proliferation signaling pathways and to the downstream expression of cell cycle regulators in order to achieve the proper proliferation rate of hepatocytes and the cell cycle synchrony during liver regeneration.

\section{Results}

Expression of GSTP1/P2 increases in regenerating liver. Following $\mathrm{PH}$, Gstp1 and p2 mRNA levels in regenerating livers increased at $2 \mathrm{~h}$ when compared with the normal liver and then dropped at $36 \mathrm{~h}$ to levels below to those found in the normal liver (Figure 1a). In agreement, the protein amounts augmented rapidly after $\mathrm{PH}$ before decreasing in a timedependent manner until $48 \mathrm{~h}$ (Figure 1b). GSTP1/P2 immunodetection showed a homogeneous staining across the hepatic lobule in the normal liver while the expression appeared mainly concentrated in periportal hepatocytes at 6 and $48 \mathrm{~h}$ in regenerating livers (Figure 1c). Consistent with western blotting results, GSTP1/P2 staining was greatly diminished at $48 \mathrm{~h}$ post-PH. Of note, GSTP1/P2 were found in the nucleus of some regenerating hepatocytes. No labeling was detected in the Gstp $1 / 2^{-/-}$mouse livers.

Loss of Gstp1/2 does not modify hepatocyte survival following $\mathrm{PH}$. After $\mathrm{PH}$, postoperative survival was similar for wild-type (WT) and Gstp1/2-/- mice when the gallbladder was kept intact. Indeed, the number and extent of bile infarcts increased in Gstp 1/2-/- mice compared with WT animals when gallbladder alterations occurred (data not shown).

In the absence of gallbladder alterations, histological analysis of regenerating livers did not reveal abnormalities or

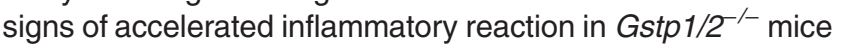
(Figure 2). Serum levels of aspartate aminotransferase (AST) and alanine aminotransferase (ALT) peaked at $12 \mathrm{~h}$ in both mice genotypes (Figures $2 \mathrm{a}$ and $\mathrm{b}$ ). Caspase 3 activity increased at $6 \mathrm{~h}$ in WT mice before returning to basal level at $12 \mathrm{~h}$ (Figure 2c). In Gstp1/2 ${ }^{-/}$mice, basal level of Caspase 3 activity was significantly higher than in the WT normal livers, and this activity did not show any increase over the time course performed. Blood levels of triglycerides, urea and bilirubin were not significantly affected and indicated that the overall liver function remained efficient in both mice genotypes (data not shown).

Invalidation of Gstp1/2 impairs hepatocyte proliferation. In WT mice, the percentage of 5-bromo-2'-deoxyuridine (BrdU)-positive hepatocytes increased at $40 \mathrm{~h}$ to reach a peak $48 \mathrm{~h}$ after $\mathrm{PH}$. Then hepatocyte DNA synthesis returned to basal level at 3 days. In the livers of Gstp $1 / 2^{-/}$mice, DNA synthesis also began at $40 \mathrm{~h}$ but did not show any sharp increase during the 72-h time post- $\mathrm{PH}$. In mutant mice, only $6.58 \pm 1.71 \%$ of hepatocytes were BrdU-positive at $48 \mathrm{~h}$ versus $37.07 \pm 10.8 \%$ in the WT livers (Figures $3 a$ and e). Mitotic index (Figure $3 \mathrm{~b}$ ) and the percentage of phosphorylated histone H3-positive hepatocytes (Figures $3 \mathrm{c}$ and $\mathrm{d}$ ) further evidenced a significant decrease in the proliferation rate in the Gstp $1 / 2^{-/}$livers compared with the WT livers. At 52 and $55 \mathrm{~h}$, the Gstp $1 / 2^{-/}$livers displayed an $\sim 3$-fold decrease in the cell numbers in G2 and M phases compared with their control counterparts. Altogether, these data indicate that lack of GSTP1/P2 significantly impaired the partially synchronized first wave of hepatocyte proliferation without abolishing totally the process of liver regeneration.

Loss of Gstp1/2 alters the expression timing of cell cycle regulator expression. To evaluate the effect of Gstp1/2 deletion on hepatocyte cycle progression, we analyzed the expression of main regulators involved in G0/G1 transition. As expected, intrahepatic protein and RNA levels as well as serum levels of TNFa rapidly increased at 1,2 and $6 \mathrm{~h}$ 
a

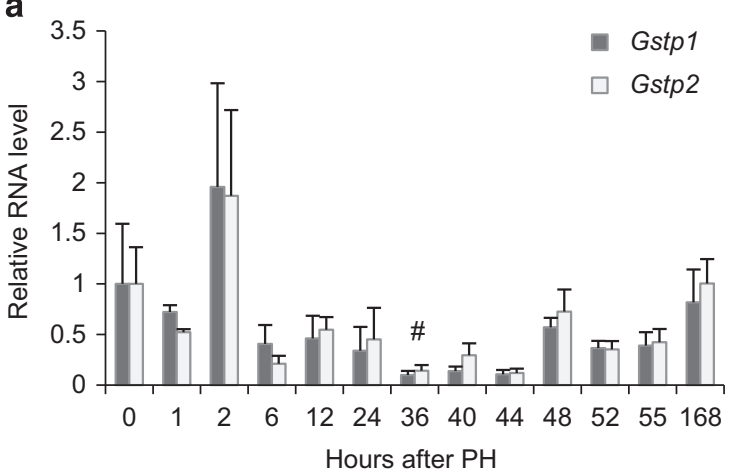

b $\begin{array}{lllllllllllll}0 & \text { KO } & 2 & 6 & 12 & 24 & 36 & 40 & 44 & 48 & 52 & 55 & 168\end{array}$

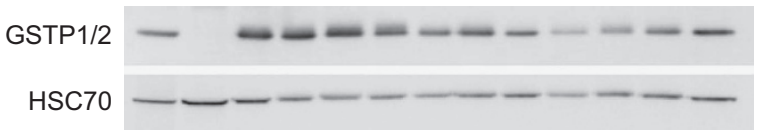

c

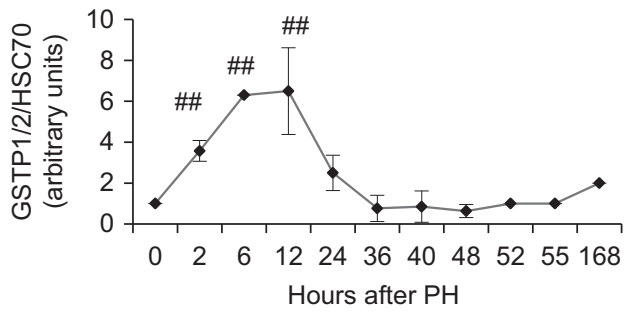

Gstp $1 / 2^{+/+}$

d

Gstp1/2-/

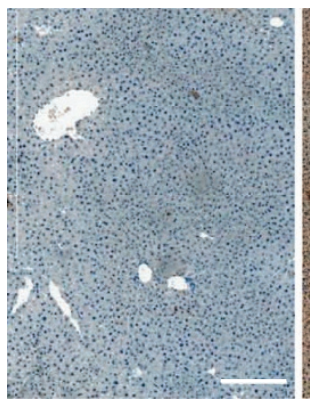

Oh

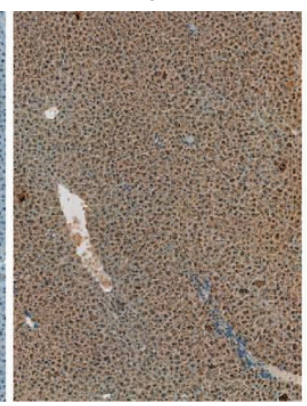

$6 \mathrm{~h}$

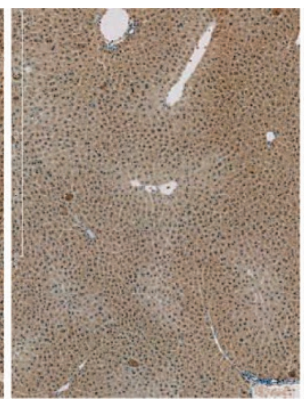

$48 \mathrm{~h}$

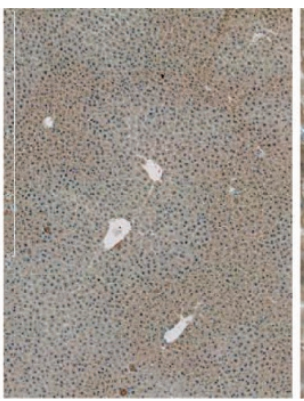

$48 h$

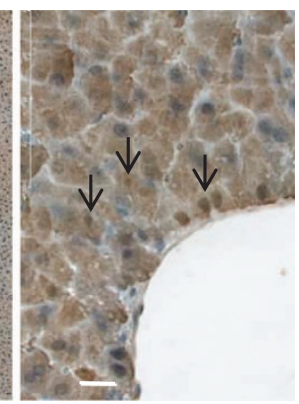

Figure 1 Expression and hepatic localization of GSTP1/2 after PH in WT mice. (a) mRNA levels of hepatic Gstp1 (grey bar) and Gstp2 (white bar) were measured by RT-qPCR at the indicated times after PH. Results are expressed as fold induction compared with the control liver arbitrarily set at 1 and as mean \pm S.E.M. ( $n=3-7$ mice/group/ time point). ${ }^{\#} P \leq 0.05,{ }^{\# \#} P \leq 0.01$, time point after PH versus normal livers. (b) Pool of total proteins from different mice were used for western blotting analyses of GSTP1/2 expression in the livers of Gstp1/2+/+ mice at the indicated times after PH. HSC70 is used as a loading control. (c) Densitometric analysis of the western blotting results of GSTP1/2 obtained from different mice $(n=3)$. (d) Immunolocalization of GSTP1/2 in the WT livers prior to PH and at 6 and $48 \mathrm{~h}$ after PH. Arrows indicate some stained nuclei. The livers of Gstp1/2-/ mice were used as negative controls. Bars: 200 or $20 \mu \mathrm{m}$

post-PH in WT mice, respectively (Figures $4 a, b$ and d). In parallel, liver RNA and serum levels of IL-6 augmented at $0.5-1$ and $6 \mathrm{~h}$ post $\mathrm{PH}$, respectively (Figures $4 \mathrm{c}$ and $\mathrm{d}$ ). In contrast, the production of TNFa and IL-6 was delayed in Gstp $1 / 2^{-/}$mice, and their serum concentration peaked after only $12 \mathrm{~h}$. The changes in IL-6 secretion correlated with the delayed phosphorylation of STAT3 in the Gstp1/2-/- livers (Figure $4 \mathrm{e}$ ) and a postponed and/or reduced expression of $c$-Fos, Jun $B$ and $c$-Jun mRNA levels during the first $24 \mathrm{~h}$ post-PH (Figure 4f). In contrast, induction of $c-M y c$ mRNAs occurred earlier, and their levels remained higher at several time points in the Gstp $1 / 2^{-/}$regenerating livers compared with the WT control livers (Figure 5a). P53 mRNA levels were also slightly higher during the first $24 \mathrm{~h}$ post-PH in $\mathrm{Gstp} 1 / \mathrm{2}^{-/-}$ mice (Figure 5a).

We further studied the time course of the expression of cell cycle regulators involved in the mid-late $\mathrm{G} 1$ phase, the G1/S transition and the DNA replication. At 36 and $40 \mathrm{~h}$, in mid-late G1 phase, the hepatic mRNA levels of $\mathrm{Hgf}$ appeared significantly lower in Gstp $1 / 2^{-/-}$along with a limited induction of Cyclin D1 mRNA levels at $40 \mathrm{~h}$ compared with their strong increase in the WT livers (Figure 5d). In agreement, the amount of Cyclin D1 protein was strongly induced in the WT regenerating livers from 36 to $48 \mathrm{~h}$ prior the onset of DNA synthesis while its expression gradually increased in a timedependent manner leading to the maximal levels after only $55 \mathrm{~h}$ in the Gstp $1 / 2^{-/}$livers (Figures $5 \mathrm{~b}$ and c). Similar patterns of expression were observed for CDK4 with a delayed induction in Gstp 1/2 ${ }^{-/}$. The expression of the proteins E2F1, Cyclin E, CDK2 and MCM7, which characterize the progression in late $\mathrm{G} 1$ phase and the commitment to DNA replication, was also postponed in Gstp $1 / 2^{-/-}$(Figure 5c). Importantly, the expression of tumor suppressor protein P53 occurred earlier in the Gstp $1 / 2^{-/-}$regenerating livers with a sharp induction at 24 and $36 \mathrm{~h}$ while in the WT livers its expression mainly detected at 40 and $44 \mathrm{~h}$ was much lower. The levels of cell cycle inhibitors $\mathrm{P} 21^{\mathrm{CIP} 1}$ and $\mathrm{P} 27^{\mathrm{Kip} 1}$ were also altered in Gstp $1 / 2^{-/-}$ reinforcing the conclusion of an impaired progression in $\mathrm{G} 1$ phase in mutant mice (Figure $5 \mathrm{c}$ ). High levels of P21 ${ }^{\mathrm{CIP} 1}$ were maintained during all the regeneration period in Gstp $1 / 2^{-/-}$ 


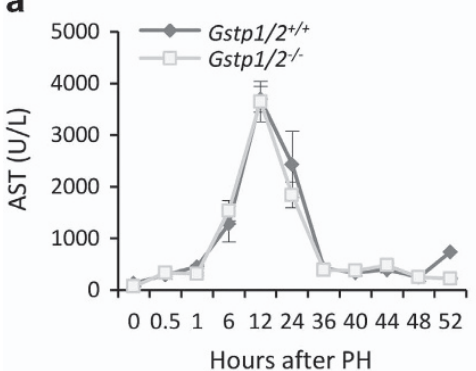

b

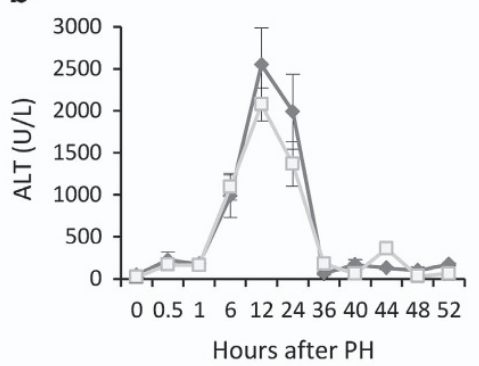

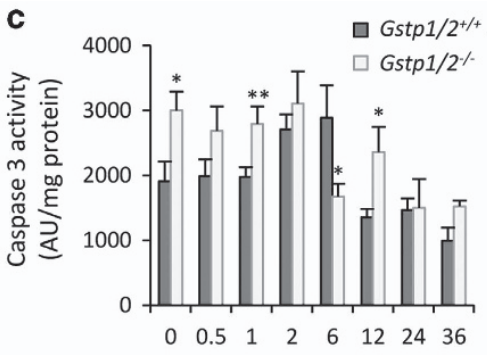

Hours after $\mathrm{PH}$

d

Gstp $1 / 2^{+/+}$

Gstp1/2\%
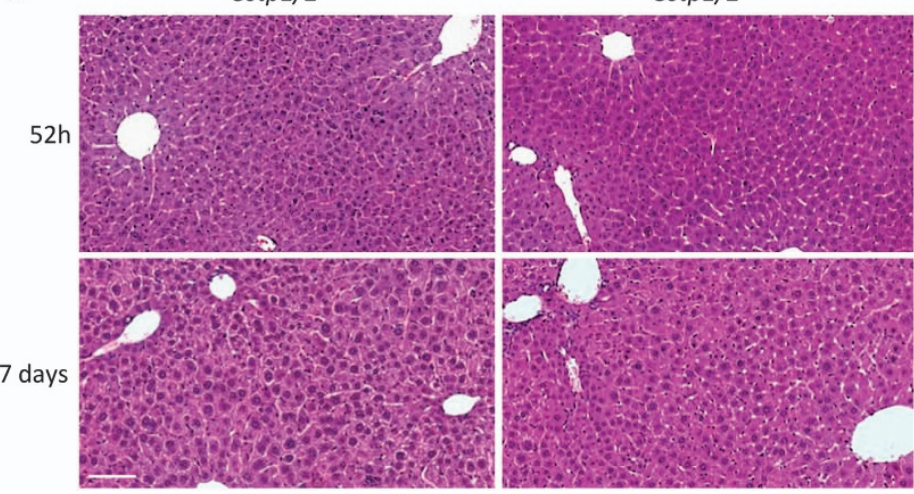

Figure 2 Transaminase levels and cell death in Gstp $1 / 2^{-/}$mice after PH. Serum levels of (a) AST and (b) ALT in Gstp $1 / 2^{+/+}$and Gstp $1 / 2^{-/}$mice at the indicated times after PH. (c) Caspase 3 activity in the liver homogenates of Gstp1/2 ${ }^{+/+}$and Gstp $1 / 2^{-/-}$mice at the indicated times after PH. Results were expressed as mean \pm S.E.M. ( $n=3-7$ mice/group/time point). ${ }^{*} P \leq 0.05,{ }^{* *} P \leq 0.01$, Gstp $1 / 2^{-/-}$versus Gstp $1 / 2^{+/+}$mice. (d) Histology of the livers from Gstp $1 / 2^{+/+}$and Gstp $1 / 2^{-/-}$mice at $52 \mathrm{~h}$ and 7 days after PH. Bar: $100 \mu \mathrm{m}$

mice, including the early time points, whereas $\mathrm{P} 21^{\mathrm{CIP} 1}$ amounts increased only at $40 \mathrm{~h}$ in the WT livers. The basal protein levels of P27 ${ }^{\text {Kip } 1}$, high in Gstp $1 / 2^{-/-}$mice, decreased rapidly from 2 up to $36 \mathrm{~h}$, whereas its expression low in the normal WT liver increased at 6 and $24 \mathrm{~h}$. Also, P27 $7^{\text {Kip } 1}$ expression was similar in both mice genotypes. Although, the induction of the Cdk1 mRNA expression was found relatively similar in both mice genotypes (Figure $5 \mathrm{~d}$ ), CDK1 protein, which is known to be expressed during DNA replication and progression in $\mathrm{G} 2$ and $\mathrm{M}$ phases, was transiently induced at 40 and $44 \mathrm{~h}$ in the WT livers while its expression increased progressively with maximal levels between 55 and $72 \mathrm{~h}$ in mutant mice (Figures $5 b$ and $c$ ).

Activation of JNK and extracellular signal-regulated kinase (ERK) signaling pathways are altered in Gstp $1 / 2^{-/-}$ mice following PH. To address the molecular mechanisms inducing the delayed liver regeneration and the alteration of cell cycle regulators expression in Gstp $1 / 2^{-/}$mice, we investigated the activation of signaling pathways. As previously reported, ${ }^{26}$ we observed a constitutive activation of JNK pathway in the Gstp $1 / 2^{-1}$ mouse livers prior to $\mathrm{PH}$ (Figure 6a). Indeed, the phosphorylation of JNK and its downstream substrates c-Jun and activating transcription factor 2 (ATF2) were higher in the livers of Gstp 1/2-/- mice than in the WT livers. Following PH, the levels of p-JNK and $\mathrm{p}$-c-Jun decreased progressively until $24 \mathrm{~h}$ while that of p-ATF2 remained stable (Figure 6a). Levels of p-JNK increased only at later time points (Figure 6b). Conversely, in WT mice, JNK pathway was activated from 2 to $40 \mathrm{~h}$ as evidenced by the enhanced phosphorylation levels of JNK, c-Jun and ATF2 (Figure 6). At later time points (40-168 h), $p$-JNK kept increasing, whereas the levels of $p$-c-Jun and p-ATF2 decreased.

Regarding P38 activation, similar profiles were obtained in WT and Gstp1/2-/- mice. Phospho-P38 expressed in the quiescent liver underwent a rapid but transient dephosphorylation lasting $24 \mathrm{~h}$ (Figure 6a). Then induction of p38 activation was observed $36 \mathrm{~h}$ after $\mathrm{PH}$ and remained stable until $168 \mathrm{~h}$ (Figure 6b). ERK1/2 activation occurred successively three times in the liver of WT mice at 2-6, 24-36 and 44-48 $\mathrm{h}$ after $\mathrm{PH}$ (Figures $6 \mathrm{a}$ and b). In Gstp $1 / \mathrm{2}^{-/-}$mice, a similar induction of ERK $1 / 2$ phosphorylation was observed at 2-6 h. In contrast, ERK $1 / 2$ phosphorylation was not induced at $24-36 \mathrm{~h}$ and was moderately increased at $44-48 \mathrm{~h}$ in mutant mice. TRAF2 transiently induced at $0.5-1 \mathrm{~h}$ in both mice genotypes was re-expressed in WT at 36 and $48-60 \mathrm{~h}$ after $\mathrm{PH}$, whereas it was barely detectable at 40 and $60 \mathrm{~h}$ in mutant mice.

Expression of stress response genes is delayed in Gstp $1 / 2^{-/}$mice after PH. ROS modulate MAPK activation such as JNK, which is essential for regulating the intracellular redox status and the balance between cell proliferation and cell death. Among the enzymes contributing to the balance of the redox system, GSTP1/P2 catalyze the elimination of electrophilic oxidants. We therefore studied the expression of enzymes involved in cell defense mechanisms. After $\mathrm{PH}$ in WT mice, RNA levels of Nrf2 increased at $36 \mathrm{~h}$ concomitantly with the induction of its two target genes, the mitochondrial 
a

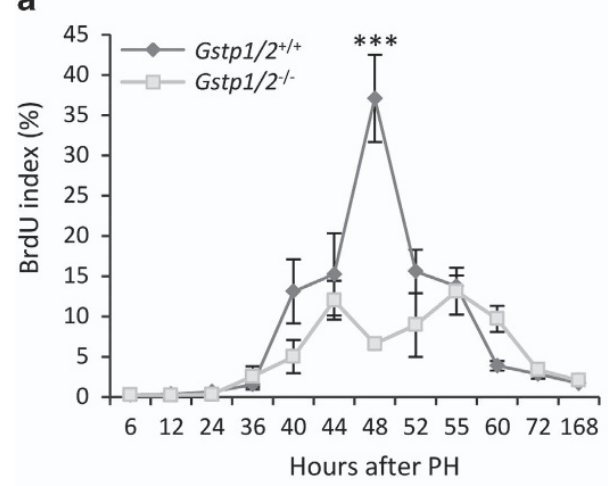

b

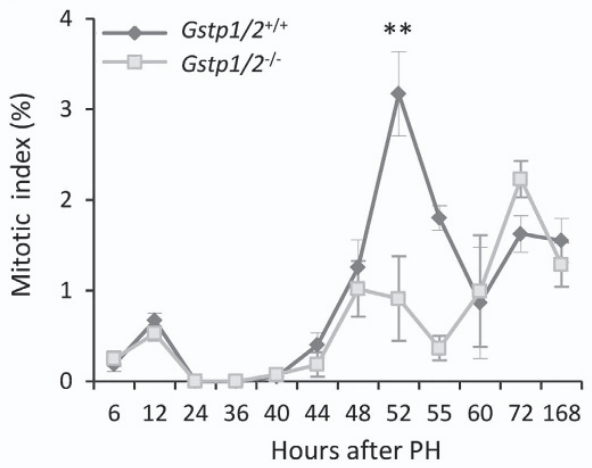

C

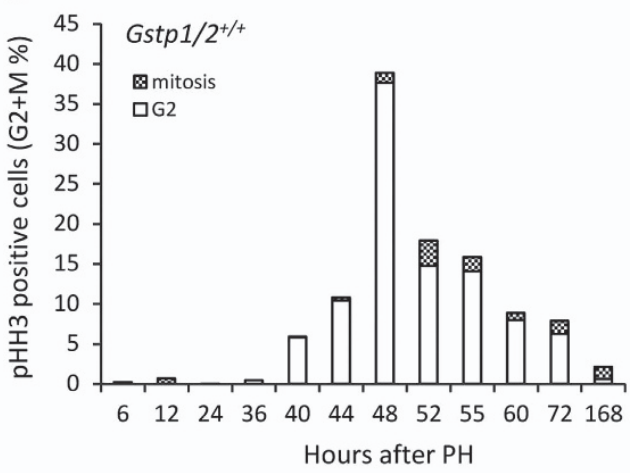

d

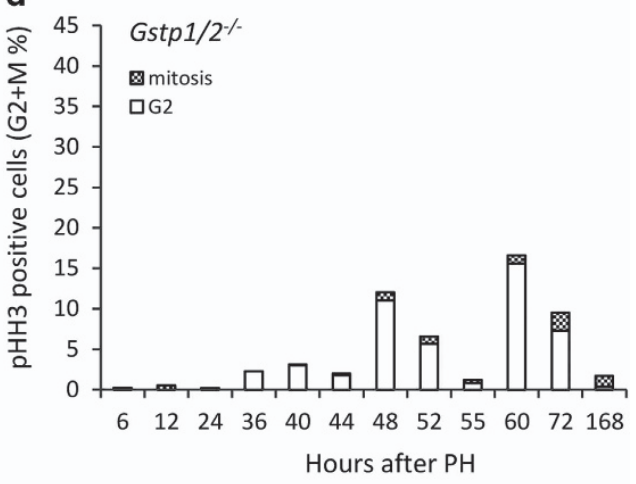

e

$44 \mathrm{~h}$

$48 \mathrm{~h}$

$55 \mathrm{~h}$

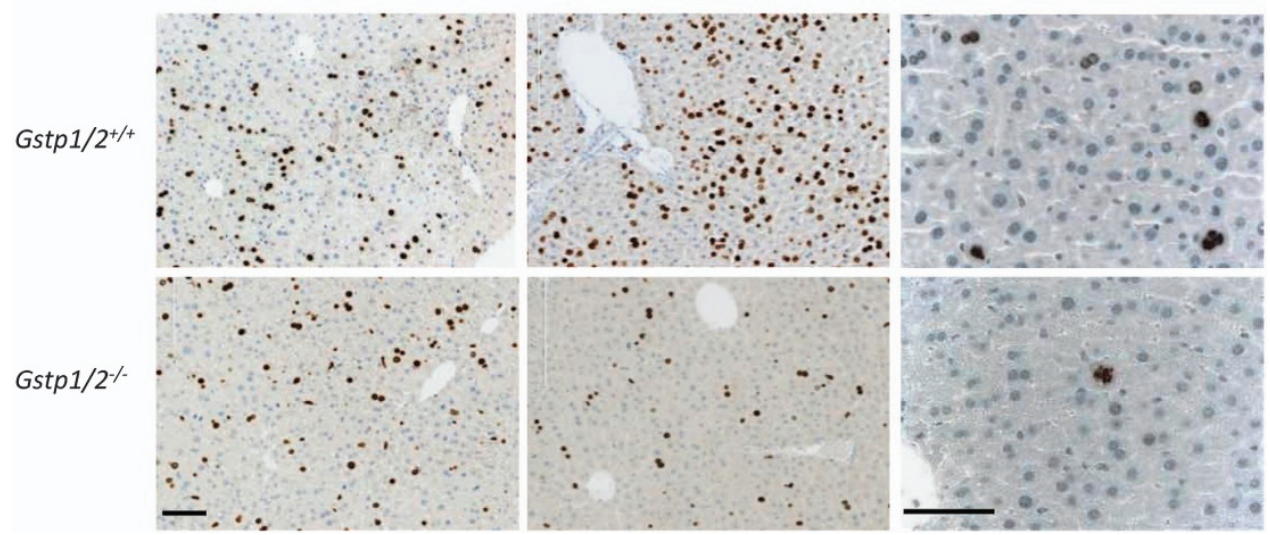

Figure 3 Defective hepatocyte proliferation in Gstp1/2-/- mice after PH. The percentage of (a) BrdU-positive hepatocytes and of (b) hepatocytes in mitosis in the Gstp1/2 $2^{+/+}$and Gstp1/2 ${ }^{-/}$mouse livers at the indicated times after PH. The percentage of phospho-histone H3 (pHH3)-positive hepatocytes in G2/M phase in the (c) Gstp1/2 $2^{+/+}$and (d) Gstp1/2 ${ }^{-1}$ livers at the indicated times after PH. Quantification was performed by analyzing at least six microscope fields (×20) per mice. Results were expressed as mean \pm S.E.M. ( $n=3-7$ mice/group/time point). ${ }^{* *} P \leq 0.01,{ }^{* * *} P \leq 0.001$, Gstp $1 / 2^{-/-}$versus WT mice. (e) Immunolocalization of BrdU or of pHH3 at the indicated times after PH, Bars: $100 \mu \mathrm{m}$

superoxide dismutase (MnSOD) and the catalase both at the RNA (Figure 7a) and protein levels (Figure 7b). Changes in NRF2 and MnSOD liver distribution were also evidenced. Mainly present in the perivenous areas, NRF2 and MnSOD expressions became more diffuse across the hepatic lobule at 24 and $36 \mathrm{~h}$ post-PH (Figure 8). Regarding heme oxygenase 1 (Hmox1), its expression both at the RNA and protein levels showed a biphasic induction at 6-24 and $60 \mathrm{~h}$ (Figures $7 \mathrm{a}$ and b). In mutant mice, the expression profiles of Nrf2, MnSOD, catalase and Hmox1 were different. No increase in Nrf2 RNA levels were detected during the regenerative response, whereas RNA and protein amounts of MnSOD and catalase increased but only at 40-44 $\mathrm{h}$ and at late time points. Consistent with these changes, NRF2 and MnSOD staining located mainly in the perivenous areas, and also in the sinusoids for NRF2 in the Gstp $1 / 2^{-1-}$ livers, became more diffuse in the hepatic lobule from $40 \mathrm{~h}$ post-PH (Figure 8). In contrast, Hmox1 RNA and protein levels progressively increased to become higher than in WT mice at $\sim 36$ and $52 \mathrm{~h}$ (Figure 7a).

Expression of $\mathrm{Hsp} 70$ involved in correct folding and elimination of misfolded proteins was similar in both mice genotypes. Hif1a mRNA expression did not differ between the control and mutant mice although the initial level of Hif1a 

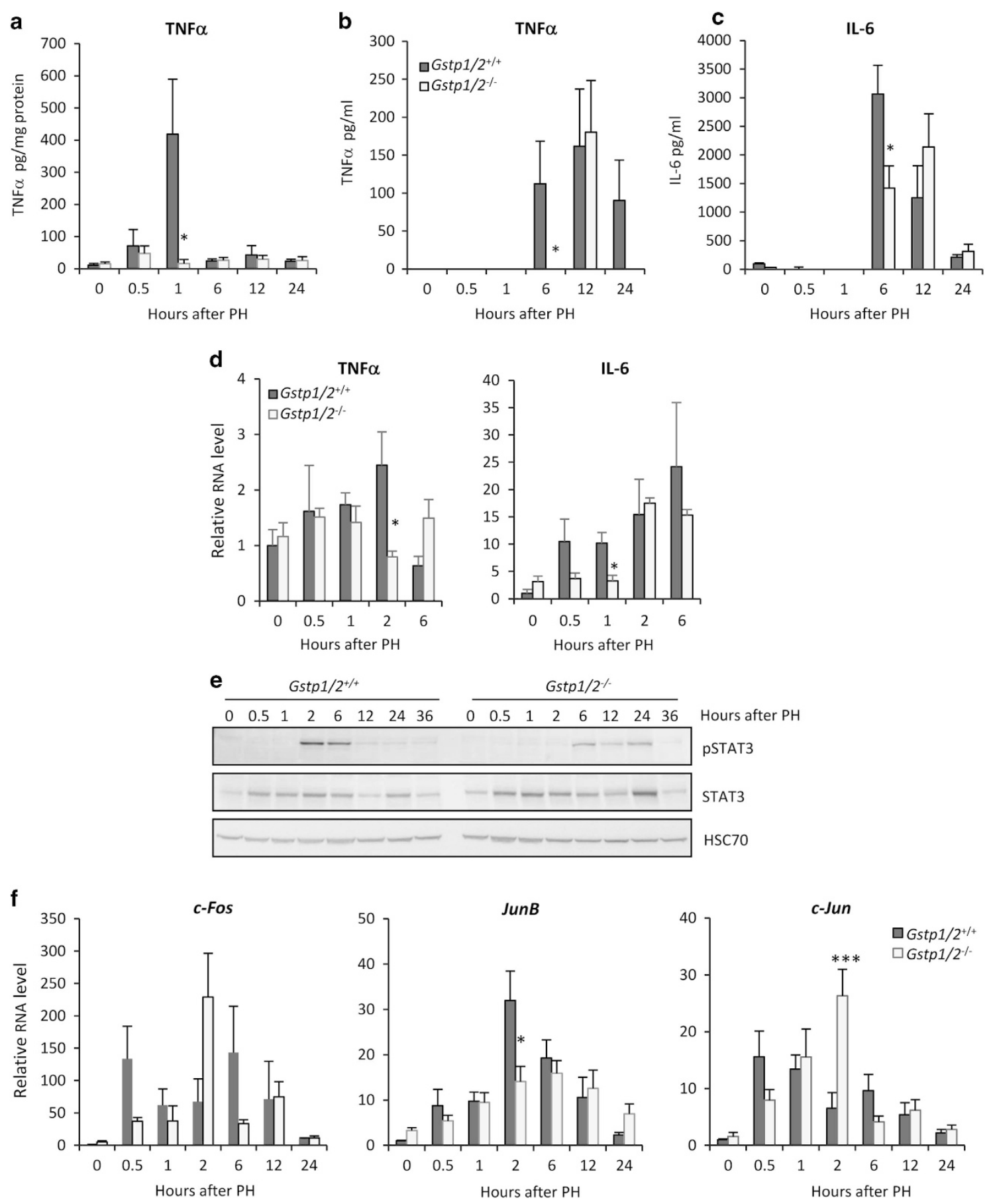

Figure 4 Alteration of the hepatocyte 'priming' after PH in Gstp1/2-/- mice. (a) Intrahepatic levels of TNF $\alpha$ and the serum levels of (b) TNF $\alpha$ and (c) IL-6 in Gstp1/2+/+ and Gstp $1 / 2^{-1-}$ mice at indicated times after PH. (d) mRNA levels of hepatic Tnf $\alpha$ and II- 6 were measured by RT-qPCR at the indicated times after PH. (e) Pool of total proteins from

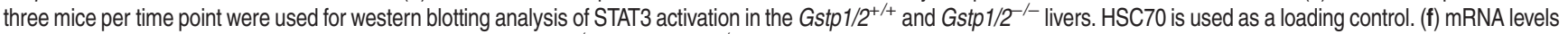
of c-Jun, c-Fos and JunB proto-oncogenes by qPCR in Gstp $1 / 2^{+/+}$and Gstp1/2-/- mice at the indicated times after PH. Results are expressed as fold induction compared with the Gstp $1 / 2^{+/+}$control liver arbitrarily set at 1 and as mean \pm S.E.M. ( $n=3-7$ mice/group/time point). ${ }^{*} P \leq 0.05,{ }^{* * *} P \leq 0.001$, Gstp $1 / 2^{-/-}$versus Gstp $1 / 2^{+/+}$mice

expression was higher in the WT livers than in the Gstp $1 / 2^{-/-}$ livers (Figure 7a).

Interestingly, the expression of the nitric oxide synthases, eNOS and iNOS, involved in NO production and hemodynamic changes was also altered in Gstp $1 / 2^{-/-}$ mice. In WT mice, eNOS RNA levels increased from 6 to $40 \mathrm{~h}$ post- $\mathrm{PH}$. This increase correlated with the accumulation of eNOS protein from 24 to $72 \mathrm{~h}$ (Figure $7 \mathrm{~b}$ ). RNA and protein levels of iNOS increased only at late stages of the regeneration, 55-60 h post-PH. In contrast, although the RNA levels of eNOS remained lower in the Gstp $1 / 2^{-1-}$ livers than those found in the WT livers, the protein was highly expressed at least from 24 to $72 \mathrm{~h}$ post-PH in the Gstp $1 / 2^{-1-}$ livers. In addition, the maximum levels of iNOS mRNA also found at 


\section{a}
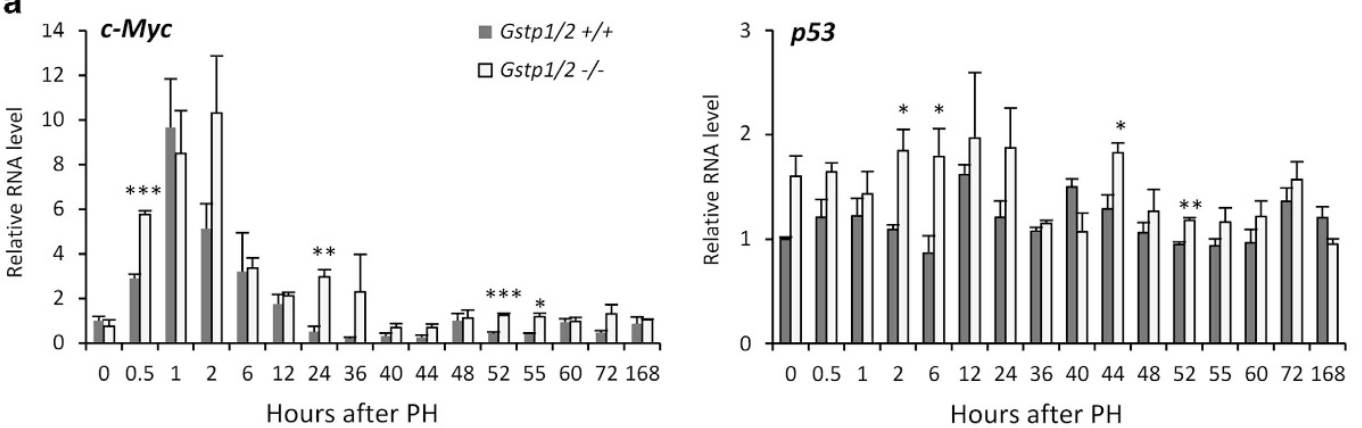

b

C

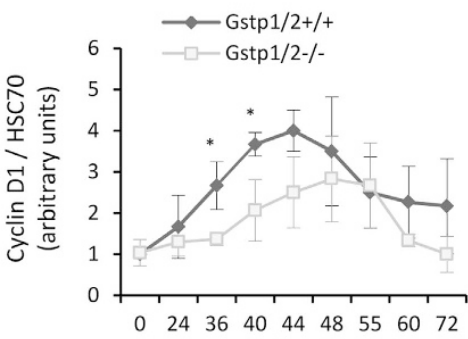

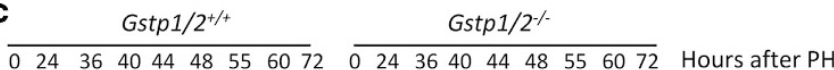

-

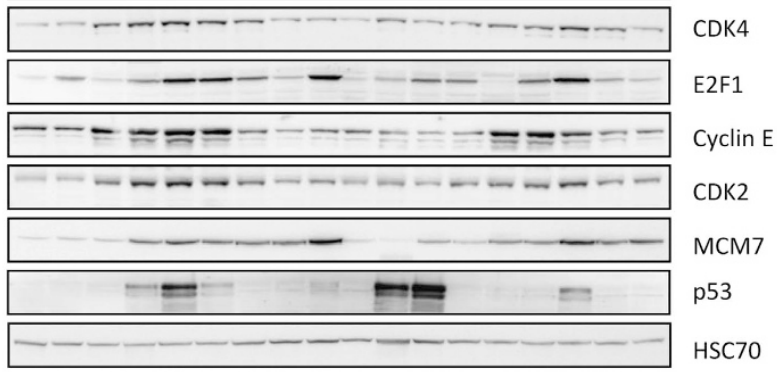

Gstp1/2+/+

Gstp1/2\%

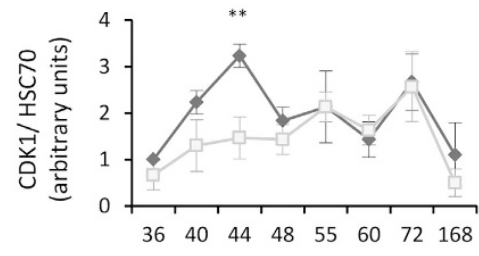

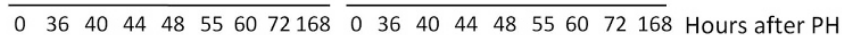

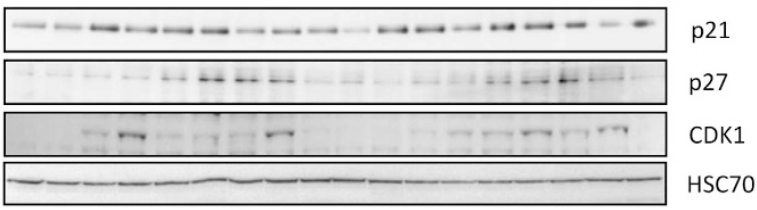

Gstp $1 / 2^{+/+} \quad$ Gstp1/2\%

\begin{tabular}{llllllllllllllllll}
\hline 0 & 0.5 & 1 & 2 & 6 & 12 & 24 & 36 & 0 & 0.5 & 1 & 2 & 6 & 12 & 24 & 36 & Hours after PH
\end{tabular}

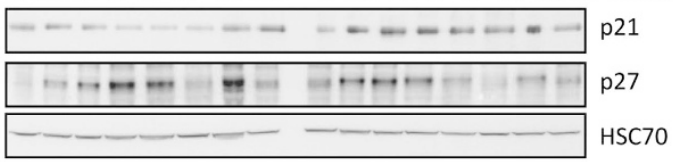

d

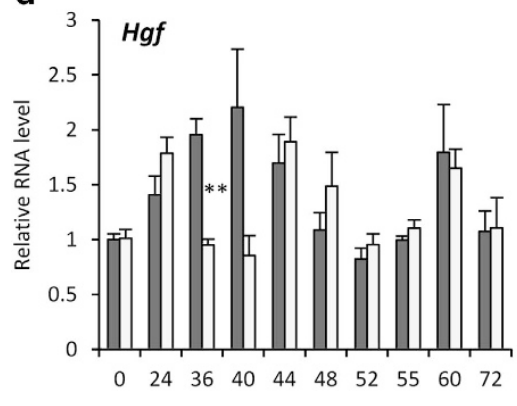

Hours after $\mathrm{PH}$

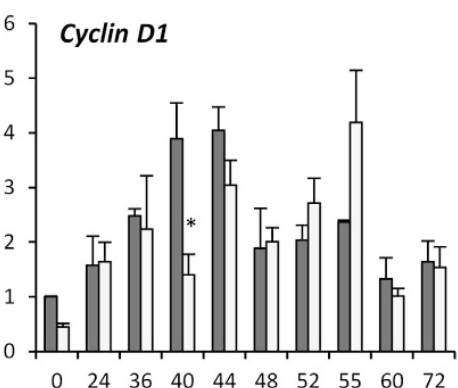

Hours after $\mathrm{PH}$

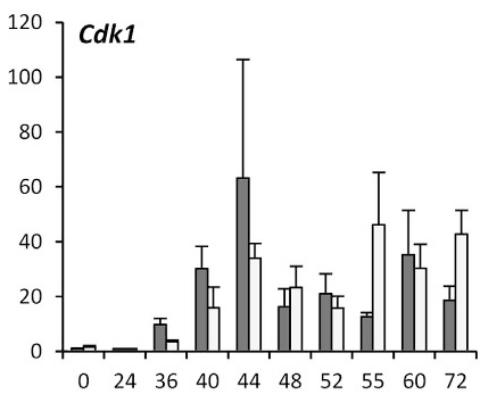

Hours after PH

Figure 5 Differential mRNA and protein expression profiles of cell cycle regulators in the livers of Gstp $1 / 2^{+/+}$and Gstp $1 / 2^{-/-}$mice after PH. (a) mRNA levels of $c-M y c$ and p53 in the Gstp $1 / 2^{+/+}$and Gstp $1 / 2^{-/-}$livers at the indicated times after PH. (b) Densitometry analysis of the western blotting results of CyclinD1 and CDK1 obtained from different mice at the indicated times $(n=3)$. (c) Pool of total proteins were used for western blotting analysis of cell cycle regulators in the livers of Gstp $1 / 2^{+/+}$and Gstp $1 / 2^{-/-}$mice at the indicated times after PH. HSC70 is used as a loading control. (d) mRNA levels of Hgf, Cyclin D1 and Cdk1 in the livers of Gstp1/2 ${ }^{+/+}$and Gstp $1 / 2^{-/-}$mice at the indicated times after PH. Results are expressed as fold induction compared with the Gstp $1 / 2^{+/+}$control liver arbitrarily set at 1 and as mean \pm S.E.M. ( $n=3-7$ mice/group/time point). ${ }^{*} P \leq 0.05$, ${ }^{* \star} P \leq 0.01,{ }^{* \star \star} P \leq 0.001$, Gstp $1 / 2^{-/-}$versus Gstp $1 / 2^{+/+}$mice 

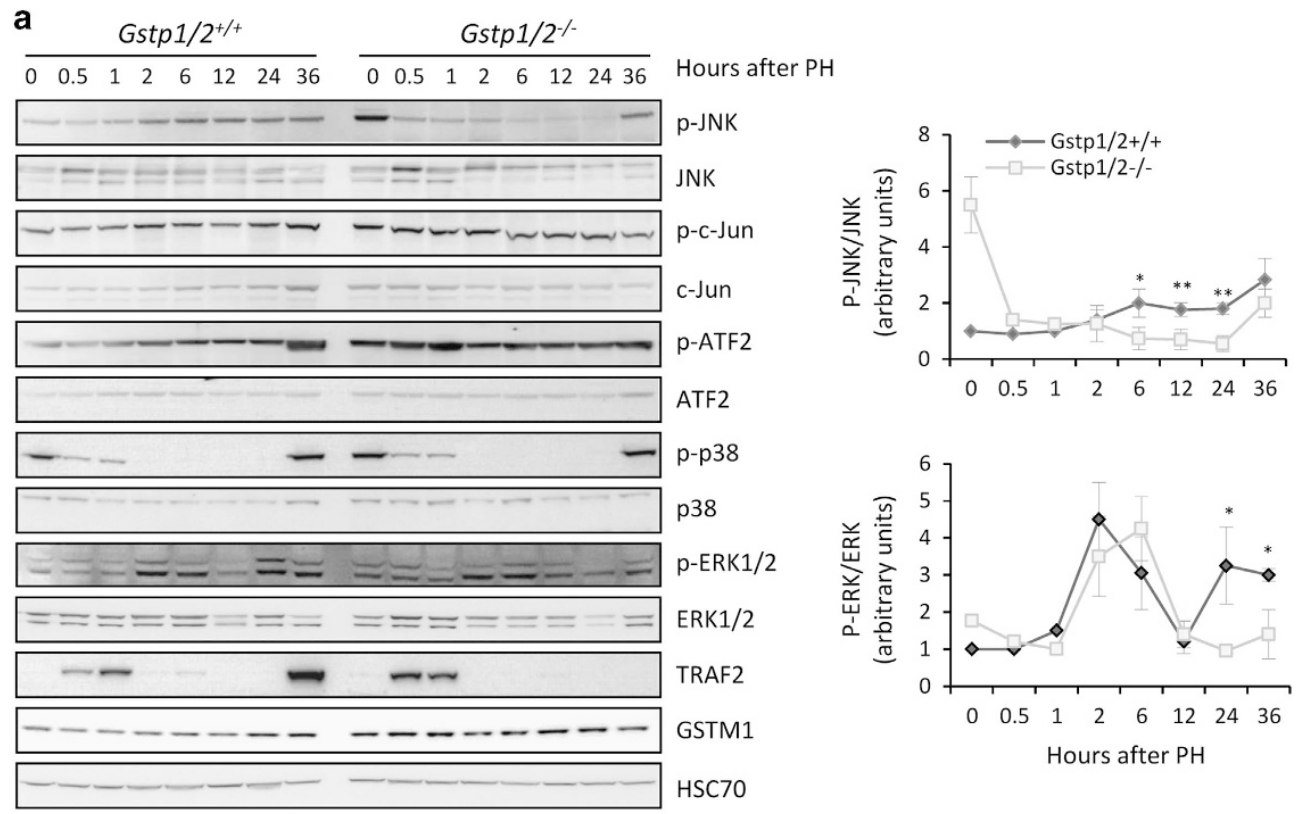

b

Gstp1/2+/+

Gstp $1 / 2 \%$

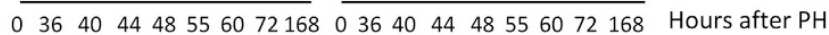
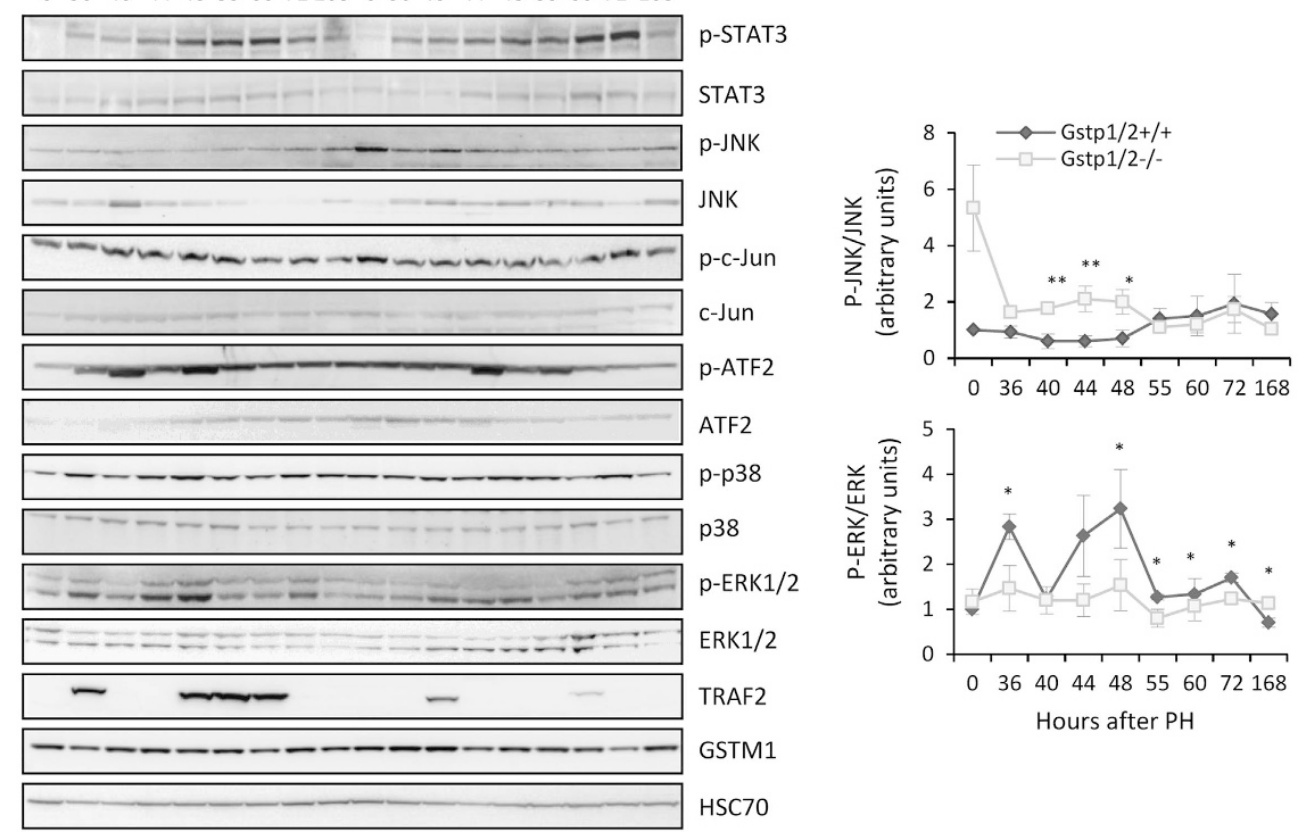

Figure 6 Cell signaling protein expression and/or activation in Gstp $1 / 2^{+/+}$and Gstp1/2- mice after PH. Pool of total proteins from three mice were used for western blotting analyses of JNK, c-Jun, ATF2, p38, ERK1/2 phosphorylation and TRAF2 and GSTM1 expression in Gstp1/2 ${ }^{+/+}$and Gstp1/2 ${ }^{-/}$mice at the indicated times after PH (a) early time points and (b) late time points. HSC70 is used as a loading control. (c) Densitometry analysis of the western blotting results of p-JNK and p-ERK obtained from different mice at the indicated times $(n=3) .{ }^{*} P \leq 0.05,{ }^{* *} P \leq 0.01$, Gstp $1 / 2^{-/-}$versus Gstp $1 / 2^{+/+}$mice

$60 \mathrm{~h}$ were significantly lower than those in the WT livers, and the protein was detected later at $60-72 \mathrm{~h}$ post-PH.

\section{Discussion}

Liver regeneration is characterized by a precise temporal pattern of events that regulate the entry into and progression through the cell cycle, including the progression beyond the mitogen-dependent restriction point in late $\mathrm{G} 1$ phase, the G1/S transition and mitosis. ${ }^{27,28}$ Our laboratory has previously shown the inductions of GSTA1, GSTA4, GSTM1 and GSTP1/P2 during mouse liver regeneration. ${ }^{29}$ Here we confirmed the early induction of GSTP1/P2 following PH and evidenced for the first time that this induction was associated with a predominant periportal intra-lobular localization. This portal zonation reinforced the hypothesis that GSTP1/P2 could 

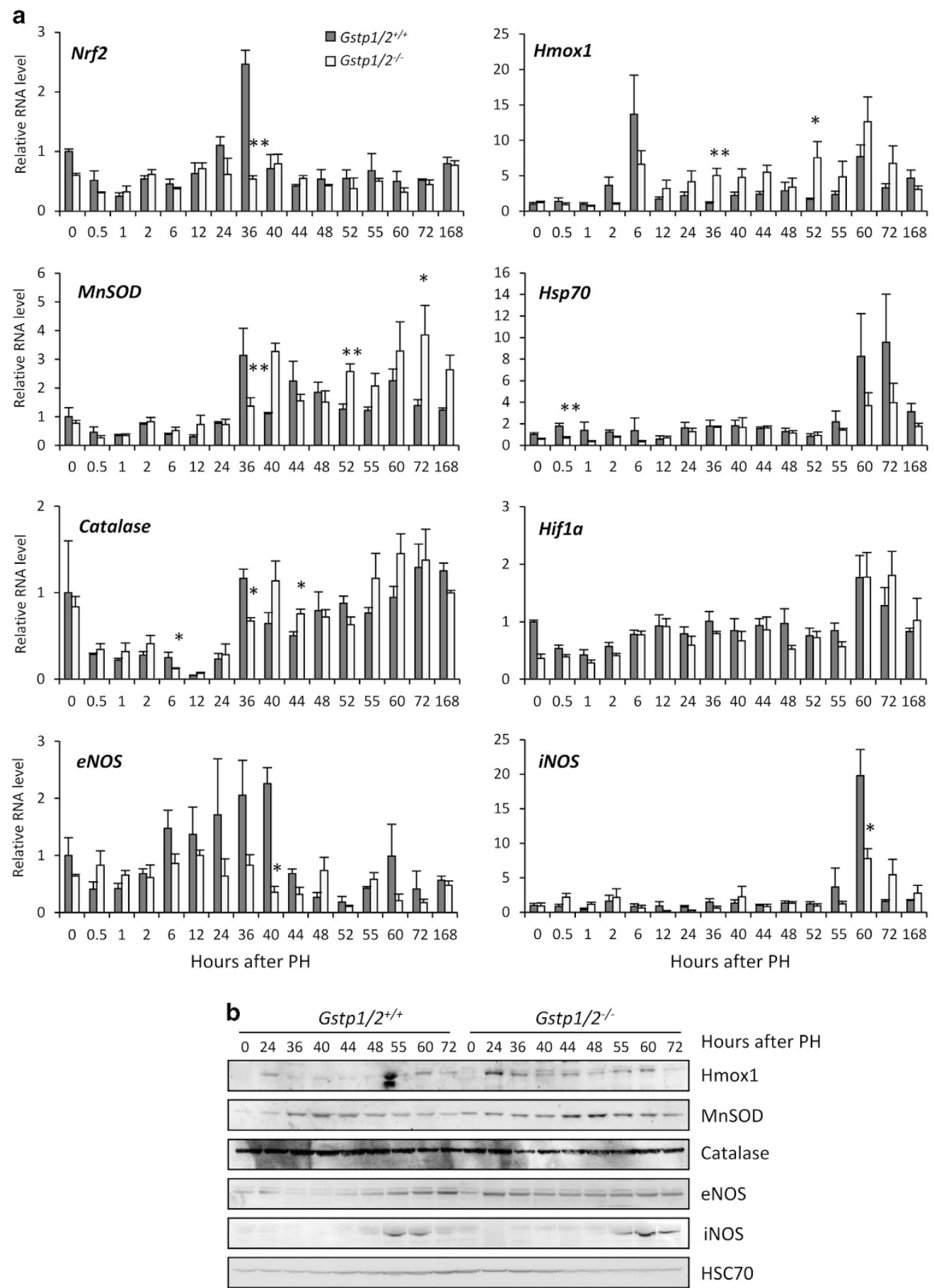

Figure 7 Differential mRNA expression of antioxidant enzymes in the livers of Gstp1/2 $2^{+/+}$and Gstp1/2 ${ }^{-/}$mice after PH. (a) mRNA of Nrf2, MnSOD, catalase, Hmox-1, Hsp70, Hif1 $\alpha$, eNOS and iNOS expression in Gstp $1 / 2^{+/+}$and Gstp $1 / 2^{-/}$mice at the indicated times after PH. Results are expressed as fold induction compared with the Gstp $1 / 2^{+/+}$control liver arbitrarily set at 1 and as mean \pm S.E.M. $\left(n=3-7\right.$ mice/group/time point). ${ }^{*} P \leq 0.05,{ }^{* *} P \leq 0.01$, Gstp $1 / 2^{-/-}$versus Gstp1/2 ${ }^{+/+}$mice. (b) Pool of total proteins from three mice per time point were used for western blotting analysis of eNOS and iNOS in Gstp1/2+/+ and Gstp1/2-- mice at the indicated times after PH. HSC70 is used as a loading control

contribute to liver regeneration as hepatocyte proliferation begins in the periportal areas ${ }^{30}$ and that gene inductions linked to cell proliferation mainly occurs in these areas. ${ }^{31}$ Using a conventional double knockout mouse model for the Gstp1 and p2 genes, we show that GSTP1/P2 is required for the activation of signaling pathways involved in liver regeneration. In WT mice, the first wave of hepatocyte proliferation is completed within $72 \mathrm{~h}$ after two-third hepatectomy. In Gstp $1 / 2^{-/}$mice, the lack of GSTP1/P2 strongly modified the chronology of the induction of cell cycle regulators and the magnitude of the proliferative response. The secretions of TNF $a$ and IL-6, the priming agents 


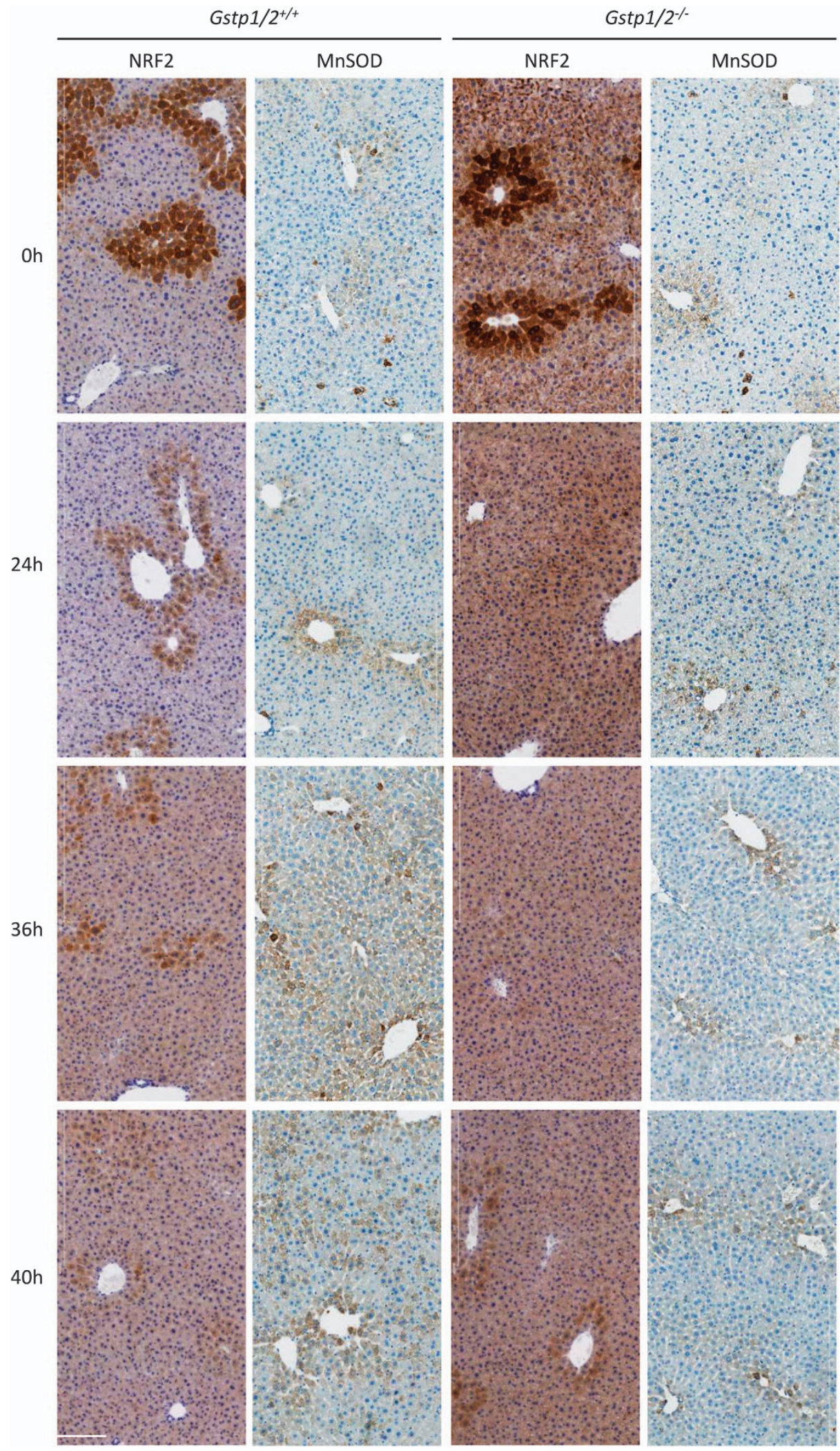

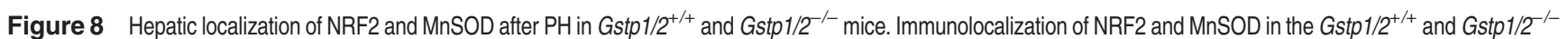
livers prior to $\mathrm{PH}(0 \mathrm{~h})$ and at 24,36 and $48 \mathrm{~h}$ after PH. Bars: $200 \mu \mathrm{m}$ 
regulating the entry into $\mathrm{G} 1$ phase, were delayed leading to a postponed induction of the immediate-early genes such as $c$-Fos and Jun-B as well as a late and reduced activation of STAT3. Then the increase in Hgfand Cyclin D1 RNA amounts, occurring at 36 and $40 \mathrm{~h}$ in WT mice, respectively, appeared only at 40 and $44 \mathrm{~h}$ in Gstp $1 / 2^{-/-}$mice. The delay in Hgf and Cyclin D1 expression also coincided with differences in the kinetics of ERK1/2 phosphorylation between the two mice genotypes, suggesting that growth factor stimulation required for hepatocyte progression up to G1/S boundary was also altered. $^{32,33}$ In both mice, the first activation of ERK1/2 signaling pathway occurred in early G1. However, the second burst of activation happening in mid-late G1 phase was lowered in Gstp 1/2 $/-$ mice, and the downstream inductions of Cyclin D1 and its catalytic partner CDK4 were delayed. This delayed induction of Cyclin D1 and CDK4 partners controlling the progression in late $\mathrm{G} 1$ phase led to alteration in E2F1 accumulation that allows the coordination of gene transcription necessary for DNA replication. Accordingly, the expression of Cyclins $E$ and A, two E2F1-target genes, and the induction of MCM7, CDK2 and CDK1 were postponed. Together, these delayed and/or reduced inductions of crucial cell cycle regulators in early and mid-late $\mathrm{G} 1$ demonstrate that the G0/G1 transition, the progression beyond the mitogendependent restriction point and the G1/S transition were significantly altered by the absence of GSTP1/2. Finally, the third burst of ERK1/2 activation associated with G2/M progression $^{34}$ was also greatly diminished and associated with a reduced number of cells replicating DNA and progressing in $\mathrm{G} 2$ and $M$ phases.

Several other MAPKinases, including P38 and JNK, also drive specific cell cycle responses following extracellular stimuli. During liver regeneration, JNK and c-Jun activations are important early events. Indeed, genetic invalidation of $\mathrm{JNK}^{5,35}$ or activation of $\mathrm{JNK}$ prior to $\mathrm{PH}^{36}$ decreases or improves hepatocyte proliferation, respectively. As previously reported, ${ }^{26}$ we found that $\mathrm{JNK}$ is constitutively activated in the control livers of Gstp $1 / 2^{-1-}$ mice as demonstrated by the high amounts of p-JNK. Unexpectedly, this activation was rapidly reduced after $\mathrm{PH}$ in Gstp $1 / 2^{-/-}$mice. This diminution of JNK activity was correlated to increased GSTM1 protein levels in the early phase of liver regeneration in the Gstp $1 / 2^{-1}$ livers. Indeed, GSTM1 inhibits the activity of the upstream regulator of JNK, the protein kinase ASK1. Concomitantly to the decrease in p-JNK levels in Gstp $1 / 2^{-1}$ mice, we observed the inactivation of its downstream substrates c-Jun and ATF2, whereas their phosphorylation levels increased in WT mice. As the c-Jun/ATF2 heterodimer induces transcription of many genes such as Cyclin D1, Cyclin A, C-Jun and Atf3, ${ }^{37}$ changes in JNK activation most likely contributes along with ERK1/2 signaling alterations to the delay in G1-to-S phase progression in Gstp $1 / 2^{-1-}$ mice. Given that the transcription factor ATF3 induces $\mathrm{P} 21^{\mathrm{CIP}}$ expression while high c-Jun activity represses P53-mediated P21 ${ }^{\mathrm{CIP}}$ induction, ${ }^{38,39}$ the precise C-Jun/ATF2 and ERK $1 / 2$ activations regulate the transient increase in p21 ${ }^{\text {CIP }}$ protein amounts required to stabilize CyclinD/CDK4/6 complexes from 36 to $40 \mathrm{~h}$ in WT mice. In contrast, in Gstp $1 / 2^{-1-}$ mice, lower activations of JNK, c-Jun/ATF2 and ERK1/2 trigger higher and longer expression of P53 and
$\mathrm{P} 21^{\mathrm{CIP}}$ that may contribute to the alterations of hepatocyte proliferation.

Considering the alterations of JNK and ERK1/2 activations in Gstp $1 / 2^{-/-}$mice, we have also investigated the expression of genes induced by the cellular redox status and hemodynamic changes that arise after liver resection. ${ }^{40,41}$ To avoid cellular and DNA damages, ROS concentration is tightly regulated during liver regeneration, and this process is achieved at least in part by the cytoprotective transcription factor Nrf2. In agreement with the lower MAPK activation in Gstp 1/2-/- mice, the transient increase in Nrf2 mRNA levels at the time of MAPK activation $(36 \mathrm{~h})$ was not observed. However, the ROS-detoxifying Nrf2 target genes, MnSOD and catalase, were eventually induced but with a significant delayed expression compared with the WT mice. Interestingly, Hmox-1 RNA levels, not increased at $6 \mathrm{~h}$ like in WT mice, were progressively augmented later and may have a protective role during liver regeneration by modulating MnSOD and catalase expression. As previously reported, $\mathrm{Hmox}-1$ expression could result from NO release in response to shear stress. ${ }^{42}$ Indeed, the high eNOS protein levels detected from 24 to $72 \mathrm{~h}$ in Gstp $1 / 2^{-/-}$mice suggests an enhanced NO production during this period of time. In parallel, the higher but transient P53 expression in Gstp $1 / 2^{-/}$mice could contribute to the maintenance of the redox homeostasis and cell survival as well as the early increase in GSTM1 protein levels that blocks the TRAF2/ASK1 signaling pathway. Accordingly, higher levels of caspase 3 activities were detected in the liver of Gstp 1/2-/- mice, and massive cell death was induced during liver dissociation performed to isolate hepatocytes (not shown). In contrast, no significant increase in caspase 3 activity and TUNEL staining (not shown) were observed after $\mathrm{PH}$.

In conclusion, although many reports previously evidenced the regulation of signaling pathways by GSTs in various in vitro cell systems, we demonstrate for the first time that the invalidation of Gstp1/p2 affects multiple key events of the hepatocyte cell cycle in vivo after $\mathrm{PH}$. Accumulation of lagging events immediately after $\mathrm{PH}$ and throughout the progression in G1, including the alteration of the finely tuned activations of JNK and ERK1/2, considerably delays the commitment to DNA replication and mitosis.

Table 1 List of the Taqman primers

\begin{tabular}{|c|c|c|}
\hline Gene & $\begin{array}{l}\text { Applied } \\
\text { denomination }\end{array}$ & Reference \\
\hline $18 S$ & RN18S & Mm03928990-g1 \\
\hline Cdk1 (cyclin-dependent kinase 1) & Cdc2a & Mm00772472-m1 \\
\hline c-Fos & Fos & $\mathrm{Mm00487425-m1}$ \\
\hline C-Jun & Jun & Mm00495062-m1 \\
\hline c-Myc & Myc & Mm00487804-m1 \\
\hline Cyclin D1 & Cond1 & $\mathrm{Mm00432359-m1}$ \\
\hline HGF (hepatocyte growth factor) & Hgf & Mm01135193-m1 \\
\hline JunB & Junb & Mm01251660-m1 \\
\hline p53 & Trp53 & Mm01731287-m1 \\
\hline TBP (TATA-binding protein) & TBP & Mm00446971-m1 \\
\hline Gstp1 (glutathione transferase P1) & Gstp1 & Mm00496606-m1 \\
\hline Gstp2 (glutathione transferase P2) & Gstp2 & Mm01231544-m1 \\
\hline
\end{tabular}




\begin{tabular}{|c|c|c|}
\hline & Forward primer $\left(5^{\prime} \rightarrow 3^{\prime}\right)$ & Reverse primer $\left(5^{\prime} \rightarrow 3^{\prime}\right)$ \\
\hline $\begin{array}{l}\text { mMnSOD (manganese superoxide dismutase) } \\
\text { mHsp70 (heat-shock protein) } \\
\text { mHmox-1 (heme-oxygenase 1) } \\
\text { mNrf2 (nuclear factor erythroid 2-related factor) } \\
\text { mTBP (TATA-binding protein) } \\
\text { mHif1a (hypoxia-inducible factor 1a) } \\
\text { mCAT (catalase) } \\
\text { mNOSi (inducible NO synthase) } \\
\text { mNOSe (endothelial NO synthase) }\end{array}$ & $\begin{array}{l}\text { TGGTGGTCCATGAGAAACAA } \\
\text { TATGCCTTCAACATGAAGAGCGCC } \\
\text { CACGCATATACCCGCTACCT } \\
\text { AGGACATGGAGCAAGTTTGC } \\
\text { AGGGGCAATGTAACACAGGT } \\
\text { GTCACCTGGYYGCTGCAATA } \\
\text { TGAGAAGCCTAAGAACGCAATTC } \\
\text { AACGGAGAACGTTGGATTTG } \\
\text { CCTTCCGCTACCAGCCAGA }\end{array}$ & $\begin{array}{l}\text { GTTTACTGCGCAATCCCAAT } \\
\text { CTTGTCCAGCACCTTCTTCTTGTC } \\
\text { CCAGAGTGTTCATTCGAGCA } \\
\text { TCTGTCAGTGTGGCTTCTGG } \\
\text { GGTGCATCGAGTCCGGTA } \\
\text { CATGATGGCTCCCTTTTTCA } \\
\text { CCCTTCGCAGCCATGTG } \\
\text { CAGCACAAGGGGTTTTCTTC } \\
\text { CAGAGATCTTCACTGCATTGGCTA }\end{array}$ \\
\hline
\end{tabular}

\section{Materials and methods}

Animal experiments. All experiments complied with ethical laws, and experimental procedures were approved by ethical committee (no. R-2010-AC-01). C57BL6/J WT (Gstp1/2 ${ }^{+/+}$) mice and Gstp1/2 knockout (Gstp1/2-/-) mice in C57BL6/ $\mathrm{J}$ background were provided by Professor Roland Wolf and Cancer Research UK ${ }^{25}$ Animals were maintained on a standard diet and housed under a 12-h light/dark cycle. Adult male mice (8- and 12-weeks old) were subjected to $70 \%$ PH under ketamine/ xylazine anesthesia. Briefly, mice were subjected to mid-ventral laparotomy, and resection of right medial, left medial and left lateral lobes were performed after separate ligation. A special care was taken to preserve the gallbladder. Remnant livers (right lateral and caudal lobes) and blood samples (collected from retro-orbital sinus under anesthesia before killing) from three to seven mice per genotype were harvested at various time points from $30 \mathrm{~min}$ to 7 days.

Liver function, histology, BrdU labeling and immunohistochemistry. Serum levels of triglycerides, ALT, AST, bilirubin and urea were measured using an automatic analyzer (Olympus automated chemistry Analyzer AU 2700; Olympus France, Rungis, France) following the manufacturer's instruction.

Hematoxylin-eosin-stained paraffin sections were performed for liver histology evaluation. Detection of GSTP1/2, NRF2 and MnSOD were performed on paraffin sections by using anti-GSTpi (PB13020, Abnova, Tebu Bio Sas, Le Perray en Yvelines, France), anti-NRF2 (sc-722, Santa Cruz Biotechnology, Santa Cruz, CA, USA) and antiMnSOD (D3X8F, Cell Signaling Technology, Beverly, MA, USA), respectively.

To measure DNA replication, a single intra-peritoneal injection of BrdU (Sigma-Aldrich, Saint-Quentin Fallavier, France; $0.5 \mathrm{mg} / \mathrm{g}$ animal weight) was realized $1 \mathrm{~h}$ before killing. Livers were fixed, and cells in S or M phases were then detected by using anti-BrdU (ab8152, Abcam, Cambridge, UK) or anti-phosphohistone H3 (no. 9701, Cell Signaling Technology), respectively. A co-staining for nucleus was performed with Hoechst. Cell counting was made with the Simple PCl software (Hamamatsu Photonics, Massy, France) on $\times 20$ pictures with at least 500 cells.

Caspase 3 activity assay. Fifty milligrams of frozen remnants livers were lysed in caspase 3 activity buffer (20 mM PIPES, $100 \mathrm{mM} \mathrm{NaCl}, 10 \mathrm{mM}$ DTT, $1 \mathrm{mM}$ EDTA, $0.1 \%$ CHAPS, $10 \%$ sucrose, pH 7.2). One hundred micrograms of proteins were incubated with $100 \mu \mathrm{M}$ DEVD-AMC at $37^{\circ} \mathrm{C}$ for $1 \mathrm{~h}$. The liberation of AMC was monitored using excitation/emission wavelength of $380 / 440 \mathrm{~nm}$ (Gemini, Molecular Devices, Saint Grégoire, France). Caspase 3 activity was measured as arbitrary fluorescent units.

Western blotting analysis and enzyme-linked immunosorbent assay (ELISA) assay. Whole liver lysates were prepared by sonication in HEPES lysis buffer (50 mM HEPES pH 7.5, $150 \mathrm{mM} \mathrm{NaCl}, 1 \mathrm{mM}$ EDTA, $2.5 \mathrm{mM}$ EGTA, $0.1 \%$ Tween $20,10 \%$ glycerol, $0.1 \mathrm{mM}$ Na orthovanadate, $1 \mathrm{mM} \mathrm{NaF}, 10 \mathrm{mM}$ $\beta$-glycerophosphate) containing protease inhibitor cocktail (EDTA-free Complete Mini, Roche, Meylan, France). Pool of total proteins extracted from three livers at each time point were performed, and proteins were separated using the NuPAGE Novex Bis-Tris 4-12\% Gels Kit (Invitrogen, Saint Aubin, France). Western blottings were performed according to the standard procedure using the following antibodies: antiGSTpi (Abnova, PB13020); anti-JNK (no. 9258), anti-phosphoJNK (no. 4671), anti-STAT3 (no. 9132), anti-phospho-STAT3 (no. 9131), anti-ATF2 (no. 9226), antiphospho-ATF2 (no. 5112), anti-p27 $7^{\text {Kip1 }}$ (no. 2552), anti-p38 (no. 9212), anti-phosphop-38 (no. 4511), anti-ERK (no. 9102), anti-phospho-ERK (no. 9101) and anti-phospho-c-Jun (no. 9261) from Cell Signaling Technology; anti-c-Jun (sc-1694), anti-CDK2 (sc-163), anti-CDK4 (sc-260), anti-Cyclin E (sc-25303),
anti-MCM7 (sc-9966), anti-p53 (sc-6243), anti-TRAF2 (sc-876), anti-HO-1 (sc-136960), anti-Nrf2 (sc-722), anti-HSC70 (sc-7298) and anti-p21 ${ }^{\text {ip1 } 1}$ (sc-397) from Santa Cruz Biotechnology; anti-iNOS (610431) and anti-eNOS (610298) from BD Transduction Laboratories, BD Biosciences, Le Pont de Claix, France; anti-E2F1 (OABB00513) from Aviva Systems Biology (CliniSciences Nanterre, France), anti-catalase (AF3398) from R\&D Systems Europe (Lille, France); and anti-MnSOD (D3X8F) from Cell Signaling Technology. Protein expression was visualized using an Enhanced Chemiluminescence Kit (ECF; Amersham Biosciences, Orsay, Fance), and the signals were quantified with scanning densitometry using the Quantity One software program (Bio-Rad Laboratories, Hercules, CA, USA). Densitometry data were normalized with the loading control HSC70 for Cyclin D1 and CDK1, total ERK for $p$-ERK and JNK for $p$-JNK.

For ELISA, liver tissues were sonicated in $50 \mathrm{mM}$ Tris- $\mathrm{HCl}$ pH 7.5, $150 \mathrm{mM} \mathrm{NaCl}$, $1 \%$ Triton X-100 and protease inhibitor cocktail (EDTA-free Complete Mini, Roche). IL-6 and TNF $\alpha$ levels were determined by the commercial ELISA assay (DY406 and DY410, respectively, R\&D Systems Europe) according to the manufacturer's guidelines.

Real-time PCR. Total RNA from remnants livers ( $n=3-7$ by time point) were extracted with RNeasy Mini Kit (QIAGEN, Courtaboeuf, France; Cat. No. 74106) following the manufacturer's instructions. Reverse transcription was performed using $1 \mu \mathrm{g}$ of total RNA with the High Capacity cDNA Reverse Transcription Kit (Applied Biosystems, Part No. 4368813). mRNA levels of various genes was determined using Taqman- or SYBR green-based quantitative PCR (qPCR) technology performed in 7900HT system (Applied Biosystems), and TBP was used as a housekeeping gene. ${ }^{43}$ Primers are listed in Tables 1 and 2.

Statistical analysis. Results are presented as mean \pm S.E.M. Statistical analyses were performed with the GraphPad 5.0 software (La Jolla, CA, USA) with ANOVA non-parametrical test and then unpaired Student's $t$-test.

\section{Conflict of Interest}

The authors declare no conflict of interest.

Acknowledgements. The authors thank the Dr. C Lucas-Clerc from the Laboratoire de Biochimie Générale, CHU Rennes, the Animal core facility ARCHE (SF Biosit, Université de Rennes 1), and the ImPACcell platform (SFR Biosit, Biogenouest, Université de Rennes 1). Programme grant support from Cancer Research UK (Professor Roland Wolf, C4639/A12330) is gratefully acknowledged. This work was supported by the Institut National de la Santé et de la Recherche Médicale, the Centre National de la Recherche Scientifique, the FEDER (Fonds Européens de Développement Régional) and the 'Contrat de plan Etat région Bretagne' (axe biothérapie). Ismail Ben Mosbah was funded by the 'Contrat de plan Etat région Bretagne' (axe biothérapie) and the Fondation pour la Recherche Médicale. Julie Pajaud was funded by the Conseil Régional de Bretagne and the Ligue Contre le Cancer-Comité d'Ille-et-Vilaine. The funders had no role in study design, data collection and analysis, decision to publish or preparation of the manuscript.

1. Fausto N, Campbell JS, Riehle KJ. Liver regeneration. Hepatology 2006; 43: S45-S53.

2. Yamada Y, Kirillova I, Peschon JJ, Fausto N. Initiation of liver growth by tumor necrosis factor: deficient liver regeneration in mice lacking type I tumor necrosis factor receptor. Proc Natl Acad Sci USA 1997; 94: 1441-1446. 
3. Cressman DE, Greenbaum LE, DeAngelis RA, Ciliberto G, Furth EE, Poli V, Taub R. Live failure and defective hepatocyte regeneration in interleukin-6-deficient mice. Science 1996; 274: $1379-1383$.

4. Diehl AM, Yin M, Fleckenstein J, Yang SQ, Lin HZ, Brenner DA, Westwick J et al. Tumor necrosis factor-alpha induces $\mathrm{c}$-jun during the regenerative response to liver injury. Am J Physiol 1994; 267: G552-G561.

5. Schwabe RF, Bradham CA, Uehara T, Hatano E, Bennett BL, Schoonhoven R, Brenner DA C-Jun-N-terminal kinase drives cyclin D1 expression and proliferation during liver regeneration. Hepatology 2003; 37: 824-832.

6. Loyer P, Cariou S, Glaise D, Bilodeau M, Baffet G, Guguen-Guillouzo C. Growth factor dependence of progression through $\mathrm{G} 1$ and $\mathrm{S}$ phases of adult rat hepatocytes in vitro. Evidence of a mitogen restriction point in mid-late G1. J Biol Chem 1996; 271: 11484-11492.

7. Albrecht JH, Hansen LK. Cyclin D1 promotes mitogen-independent cell cycle progression in hepatocytes. Cell Growth Differ 1999; 10: 397-404.

8. Corlu A, Loyer P. Regulation of the g1/s transition in hepatocytes: involvement of the cyclindependent kinase cdk1 in the DNA replication. Int J Hepatol 2012; 2012: 689324.

9. Jaumot M, Estanyol JM, Serratosa J, Agell N, Bachs O. Activation of cdk4 and cdk2 during rat liver regeneration is associated with intranuclear rearrangements of cyclin-cdk complexes. Hepatology 1999; 29: 385-395.

10. Wada T, Stepniak E, Hui L, Leibbrandt A, Katada T, Nishina H, Wagner EF et al. Antagonistic control of cell fates by JNK and p38-MAPK signaling. Cell Death Differ 2008; 15: 89-93.

11. Guegan JP, Fremin C, Baffet G. The MAPK MEK1/2-ERK1/2 pathway and its implication in hepatocyte cell cycle control. Int J Hepatol 2012; 2012: 328372.

12. Hayes JD, Pulford DJ. The glutathione S-transferase supergene family: regulation of GST and the contribution of the isoenzymes to cancer chemoprotection and drug resistance. Crit Rev Biochem Mol Biol 1995; 30: 445-600.

13. Hayes JD, Flanagan JU, Jowsey IR. Glutathione transferases. Annu Rev Pharmacol Toxicol 2005; 45: 51-88.

14. Laborde E. Glutathione transferases as mediators of signaling pathways involved in cell proliferation and cell death. Cell Death Differ 2010; 17: 1373-1380.

15. Board PG, Menon D. Glutathione transferases, regulators of cellular metabolism and physiology. Biochim Biophys Acta 2012; 1830: 3267-3288

16. Bogaards JJ, Venekamp JC, van Bladeren PJ. Stereoselective conjugation of prostaglandin $\mathrm{A} 2$ and prostaglandin $\mathrm{J} 2$ with glutathione, catalyzed by the human glutathione $\mathrm{S}$-transferases A1-1, A2-2, M1a-1a, and P1-1. Chem Res Toxicol 1997; 10: 310-317.

17. Dwivedi S, Sharma A, Patrick B, Sharma R, Awasthi YC. Role of 4-hydroxynonenal and its metabolites in signaling. Redox Rep 2007; 12: 4-10.

18. Romero L, Andrews K, Ng L, O'Rourke K, Maslen A, Kirby G. Human GSTA1-1 reduces c-Jun N-terminal kinase signalling and apoptosis in Caco-2 cells. Biochem J 2006; 400 : $135-141$

19. Desmots F, Loyer P, Rissel M, Guillouzo A, Morel F. Activation of C-Jun N-terminal kinase is required for glutathione transferase $A 4$ induction during oxidative stress, not during cell proliferation, in mouse hepatocytes. FEBS Lett 2005; 579: 5691-5696.

20. Cho SG, Lee YH, Park HS, Ryoo K, Kang KW, Park J, Eom SJ et al. Glutathione S-transferase mu modulates the stress-activated signals by suppressing apoptosis signalregulating kinase 1. J Biol Chem 2001; 276: 12749-12755.

21. Gilot D, Loyer P, Corlu A, Glaise D, Lagadic-Gossmann D, Atfi A, Morel F et al. Liver protection from apoptosis requires both blockage of initiator caspase activities and inhibition of ASK1/JNK pathway via glutathione S-transferase regulation. J Biol Chem 2002; 277 49220-49229.

22. Adler V, Yin Z, Fuchs SY, Benezra M, Rosario L, Tew KD, Pincus MR et al. Regulation of JNK signaling by GSTp. EMBO J 1999; 18: 1321-1334.

23. Sau A, Filomeni G, Pezzola S, D'Aguanno S, Tregno FP, Urbani A, Serra M et al. Targeting GSTP1-1 induces JNK activation and leads to apoptosis in cisplatin-sensitive and -resistan human osteosarcoma cell lines. Mol Biosyst 2011; 8: 994-1006.

24. Wuestefeld T, Pesic M, Rudalska R, Dauch D, Longerich T, Kang TW, Yevsa T et al. A Direct in vivo RNAi screen identifies MKK4 as a key regulator of liver regeneration. Cell 2013; 153 389-401.

25. Henderson CJ, Smith AG, Ure J, Brown K, Bacon EJ, Wolf CR. Increased skin tumorigenesis in mice lacking pi class glutathione S-transferases. Proc Natl Acad Sci USA 1998; 95: $5275-5280$.
26. Elsby R, Kitteringham NR, Goldring CE, Lovatt CA, Chamberlain M, Henderson CJ, Wolf CR et al. Increased constitutive C-Jun $\mathrm{N}$-terminal kinase signaling in mice lacking glutathione S-transferase Pi. J Biol Chem 2003; 278: 22243-22249.

27. Fausto N, Campbell JS, Riehle KJ. Liver regeneration. J Hepatol 2012; 57: 692-694.

28. Michalopoulos GK. Liver regeneration. J Cell Physiol 2007; 213: 286-300.

29. Desmots F, Rissel M, Gilot D, Lagadic-Gossmann D, Morel F, Guguen-Guillouzo C Guillouzo A et al. Pro-inflammatory cytokines tumor necrosis factor alpha and interleukin-6 and survival factor epidermal growth factor positively regulate the murine GSTA4 enzyme in hepatocytes. J Biol Chem 2002; 277: 17892-17900.

30. Rabes HM. Kinetics of hepatocellular proliferation as a function of the microvascular structure and functional state of the liver. Ciba Found Symp 1977; (55): 31-53.

31. Michalopoulos GK. Liver regeneration after partial hepatectomy: critical analysis of mechanistic dilemmas. Am J Pathol 2009; 176: 2-13.

32. Talarmin H, Rescan C, Cariou S, Glaise D, Zanninelli G, Bilodeau M, Loyer P et al. The mitogen-activated protein kinase kinase/extracellular signal-regulated kinase cascade activation is a key signalling pathway involved in the regulation of $G(1)$ phase progression in proliferating hepatocytes. Mol Cell Biol 1999; 19: 6003-6011.

33. Meloche S, Pouyssegur J. The ERK $1 / 2$ mitogen-activated protein kinase pathway as a master regulator of the G1- to S-phase transition. Oncogene 2007; 26: 3227-3239.

34. Factor VM, Seo D, Ishikawa T, Kaposi-Novak P, Marquardt JU, Andersen JB, Conner EA et al. Loss of c-Met disrupts gene expression program required for G2/M progression during liver regeneration in mice. PLoS One 2010; 5: e12739.

35. Hui L, Zatloukal K, Scheuch H, Stepniak E, Wagner EF. Proliferation of human HCC cells and chemically induced mouse liver cancers requires JNK1-dependent p21 downregulation. J Clin Invest 2008; 118: 3943-3953.

36. Duval H, Mbatchi SF, Grandadam S, Legendre C, Loyer P, Ribault C, Piquet-Pellorce C et al. Reperfusion stress induced during intermittent selective clamping accelerates rat liver regeneration through JNK pathway. J Hepatol 2010; 52: 560-569.

37. Vlahopoulos SA, Logotheti S, Mikas D, Giarika A, Gorgoulis V, Zoumpourlis V. The role of ATF-2 in oncogenesis. Bioessays 2008; 30: 314-327.

38. Stepniak E, Ricci R, Eferl R, Sumara G, Sumara I, Rath M, Hui L et al. c-Jun/AP-1 controls liver regeneration by repressing p53/p21 and p38 MAPK activity. Genes Dev 2006; 20: 2306-2314.

39. Oh YK, Lee HJ, Jeong MH, Rhee M, Mo JW, Song EH, Lim JY et al. Role of activating transcription factor 3 on TAp73 stability and apoptosis in paclitaxel-treated cervical cancer cells. Mol Cancer Res 2008; 6: 1232-1249.

40. Mei Y, Thevananther S. Endothelial nitric oxide synthase is a key mediator of hepatocyte proliferation in response to partial hepatectomy in mice. Hepatology 2011; 54: 1777-1789.

41. Son Y, Cheong YK, Kim NH, Chung HT, Kang DG, Pae HO. Mitogen-activated protein kinases and reactive oxygen species: how can ROS activate MAPK pathways? J Signal Transduct 2011; 2011: 792639.

42. Chen K, Maines MD. Nitric oxide induces heme oxygenase-1 via mitogen-activated protein kinases ERK and p38. Cell Mol Biol (Noisy-le-grand) 2000; 46: 609-617.

43. Tatsumi K, Ohashi K, Taminishi S, Okano T, Yoshioka A, Shima M. Reference gene selection for real-time RT-PCR in regenerating mouse livers. Biochem Biophys Res Commun 2008; 374: $106-110$.

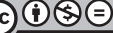

Cell Death and Disease is an open-access journal published by Nature Publishing Group. This work is licensed under a Creative Commons Attribution-NonCommercialNoDerivs 3.0 Unported License. The images or other third party material in this article are included in the article's Creative Commons license, unless indicated otherwise in the credit line; if the material is not included under the Creative Commons license, users will need to obtain permission from the license holder to reproduce the material. To view a copy of this license, visit http://creativecommons.org/ licenses/by-nc-nd/3.0/ 